\title{
Ultradeep targeted sequencing reveals low allele frequencies of somatic JAK2 and MPL variants in patients with abdominal vein thromboses: results of an ongoing prospective prevalence study in Mecklenburg-West Pomerania
}

Luise Grunwald, Christina Grosse-Thie, Sina Sender, Gudrun Knuebel, Saskia Krohn, Catrin Roolf, Christian Junghanss, Larissa Henze and Hugo Murua Escobar ${ }^{*}$ (D)

\begin{abstract}
Myeloproliferative neoplasms are characterized by mutations in JAK2, MPL and CALR genes. Commonly in diagnostics and previous studies mainly sequencing and common PCR techniques under conventional detection limits are used. Splanchnic vein thromboses are rare, but often appear associated with myeloproliferative neoplasms and represent serious complications.

Herein, blood from patients with abdominal vein thromboses in Mecklenburg-West Pomerania (federal district of northern Germany), included in an ongoing prospective prevalence study, was analyzed by next generation sequencing representing the complete protein coding regions of JAK2, MPL and CALR genes with a coverage of > 2000 reads, therefore an ultradeep targeting approach.

JAK2 V617F mutations were detected in 11/44 patients. In four of these cases allele frequencies ranged below the conventional cut off of $2 \%$. MPL W515R was detected in 3/44 cases in low frequencies.

Very low allele frequencies of JAK2 and MPL variants in patients with abdominal vein thromboses may indicate early manifestations of myeloproliferative neoplasms.
\end{abstract}

Keywords: Molecular genetics, Blood coagulation, Myeloproliferative neoplasms, Splanchnic vein thrombosis, Next generation sequencing, Ultradeep targeted sequencing, Low variant allele frequencies, JAK2, MPL

\footnotetext{
* Correspondence: hugo.murua.escobar@med.uni-rostock.de Department of Medicine, Clinic III - Hematology, Oncology, Palliative Medicine, Rostock University Medical Center, University of Rostock, Ernst-Heydemann-Str. 6, D-18055 Rostock, Germany
}

(c) The Author(s). 2020 Open Access This article is licensed under a Creative Commons Attribution 4.0 International License, which permits use, sharing, adaptation, distribution and reproduction in any medium or format, as long as you give appropriate credit to the original author(s) and the source, provide a link to the Creative Commons licence, and indicate if changes were made. The images or other third party material in this article are included in the article's Creative Commons licence, unless indicated otherwise in a credit line to the material. If material is not included in the article's Creative Commons licence and your intended use is not permitted by statutory regulation or exceeds the permitted use, you will need to obtain permission directly from the copyright holder. To view a copy of this licence, visit http://creativecommons.org/licenses/by/4.0/. The Creative Commons Public Domain Dedication waiver (http://creativecommons.org/publicdomain/zero/1.0/) applies to the data made available in this article, unless otherwise stated in a credit line to the data. 
To the editor:

Splanchnic vein thromboses (SVT) are discussed as first manifestations of myeloproliferative neoplasms (MPN) [1]. JAK2 V617F single nucleotide variants [2] were described to be found in 25 to $41 \%$ of patients with SVT [3]. In addition to JAK2 mutations, MPL and CALR mutations are known as driver mutations for MPN. Conventional qPCR and digital droplet PCR (ddPCR) allow sensitive detection of low variant allele frequencies (VAF), but do not allow the simultaneous complex screening of genetic variants. Further in contrast to next generation sequencing (NGS) an efficient identification of novel somatic variants is not possible. Accordingly, prevalence data of JAK2, MPL and CALR variants were predominantly collected qualitatively and infrequently considering the actual allele frequency [4].

Ultradeep NGS combines the advantages of high sensitivity and of simultaneously analyzing multiple gene loci. We analyzed the prevalence of JAK2, MPL and CALR variants affecting the respective protein coding sequences using an ultradeep targeted sequencing approach.

A prospective prevalence study was started in Mecklenburg-West Pomerania to elucidate the prevalence of JAK2 mutations in patients with abdominal vein thromboses. The study included patients from Mecklenburg-Western Pomerania who suffered from current or previous abdominal vein thromboses. The patient's written consent and a completed clinical questionnaire was required to analyze the blood sample within the study. There were no exclusion criteria. In blood samples from 44 patients with abdominal vein thromboses we detected in thirteen cases JAK2 V617F and MPL W515R variants including seven mutations below the conventional NGS detection limit of $2 \%$ : four JAK2 V617F variants as well as three MPL W515R variants (Table 1). One case showed the co-presence of the JAK2 V617F mutation with MPL W515R (Table 1). CALR type I and II mutations were not detected. Besides the hot spot mutations 170 further mutations were detected (data not shown).

Clinical data of the thirteen patients affected by JAK2 and MPL hot spot variants showed a variety in thrombus localization, with portal vein thromboses being the most common (11/13) (Table 1). In three patients with $\mathrm{VAF} \geq 2 \%$ for the JAK2 V617F mutation splenomegaly was present. Blood cell counts were distributed over a wide range with no obvious differences between patients with $\mathrm{VAF} \geq 2 \%$ and $<2 \%$ (Fig. 1 ). We noticed a tendency for patients with $\mathrm{VAF}<2 \%$ to be older (mean age 66.5 years, range 60 to 77 years) compared to patients carrying mutations in higher allele frequencies (mean age 61.5 years, range 48 to 73 years). This is possibly linked to age-related clonal hematopoiesis (ARCH) where the JAK2 V617F mutation has been observed recently [5].

Most previous studies in patients with SVT reported the prevalence of JAK2 V617F mutation, seldom informing about the sensitivity of the applied method [6] and rarely reporting allele frequencies [4]. By ultradeep targeted sequencing here seven additional mutations were observed, therefore increasing the prevalence of MPNrelated mutations in our cohort of 44 patients from 15.9 to $29.5 \%$. These findings support the currently discussed assumption that SVT may represent early manifestations or even precursors of MPN [1]. This is in line with a cohort study of 152 patients with SVT by Colaizzo et al.

Table 1 Thrombus localization in patients affected by JAK2 V617F and/or MPL W515R mutations (n.k. = not known)

\begin{tabular}{|c|c|c|c|c|c|c|c|c|c|c|}
\hline \multirow[t]{2}{*}{$\begin{array}{l}\text { Sample } \\
\text { No. }\end{array}$} & \multicolumn{2}{|c|}{$\begin{array}{l}\text { JAK2 } \\
\text { p.V617F; c.1849G > T; } \\
\text { NM_004972.3 }\end{array}$} & \multicolumn{2}{|c|}{$\begin{array}{l}\text { MPL } \\
\text { p.W515R; c.1543 T > C; } \\
\text { NM_005373.2 }\end{array}$} & \multirow[t]{2}{*}{$\begin{array}{l}\text { Portal } \\
\text { vein }\end{array}$} & \multirow[t]{2}{*}{$\begin{array}{l}\text { Hepatic } \\
\text { veins }\end{array}$} & \multirow[t]{2}{*}{$\begin{array}{l}\text { Splenic } \\
\text { vein }\end{array}$} & \multirow[t]{2}{*}{$\begin{array}{l}\text { Mesenteric } \\
\text { veins }\end{array}$} & \multirow[t]{2}{*}{$\begin{array}{l}\text { Other } \\
\text { veins }\end{array}$} & \multirow[t]{2}{*}{ Which } \\
\hline & VAF & Base coverage & VAF & Base coverage & & & & & & \\
\hline MPN11 & $13.2 \%$ & 7521 & & & + & n.k. & + & + & + & Confluens venae portae \\
\hline MPN18 & $31.4 \%$ & 35,994 & & & + & n.k. & n.k. & n.k. & n.k. & \\
\hline MPN30 & $24.6 \%$ & 11,120 & & & + & n.k. & n.k. & n.k. & n.k. & \\
\hline MPN38 & $43.0 \%$ & 3762 & & & + & n.k. & n.k. & n.k. & n.k. & \\
\hline MPN42 & $16.8 \%$ & 7886 & & & + & + & + & n.k. & - & \\
\hline MPN44 & $13.2 \%$ & 11,159 & & & + & - & - & - & - & \\
\hline MPN43 & $28.2 \%$ & 33,106 & $0.2 \%$ & 19,432 & + & n.k. & n.k. & n.k. & n.k. & \\
\hline MPN33 & & & $1.2 \%$ & 28,368 & - & - & - & + & - & \\
\hline MPN46 & & & $0.4 \%$ & 8303 & + & n.k. & n.k. & n.k. & n.k. & \\
\hline MPN28 & $0.2 \%$ & 5962 & & & + & n.k. & n.k. & n.k. & n.k. & \\
\hline MPN34 & $0.6 \%$ & 8567 & & & + & - & + & + & n.k. & \\
\hline MPN36 & $1.4 \%$ & 10,976 & & & - & - & - & - & + & Vena renalis sinistra \\
\hline MPN45 & $0.3 \%$ & 7628 & & & + & - & - & - & + & Plexus venosus uteri \\
\hline
\end{tabular}



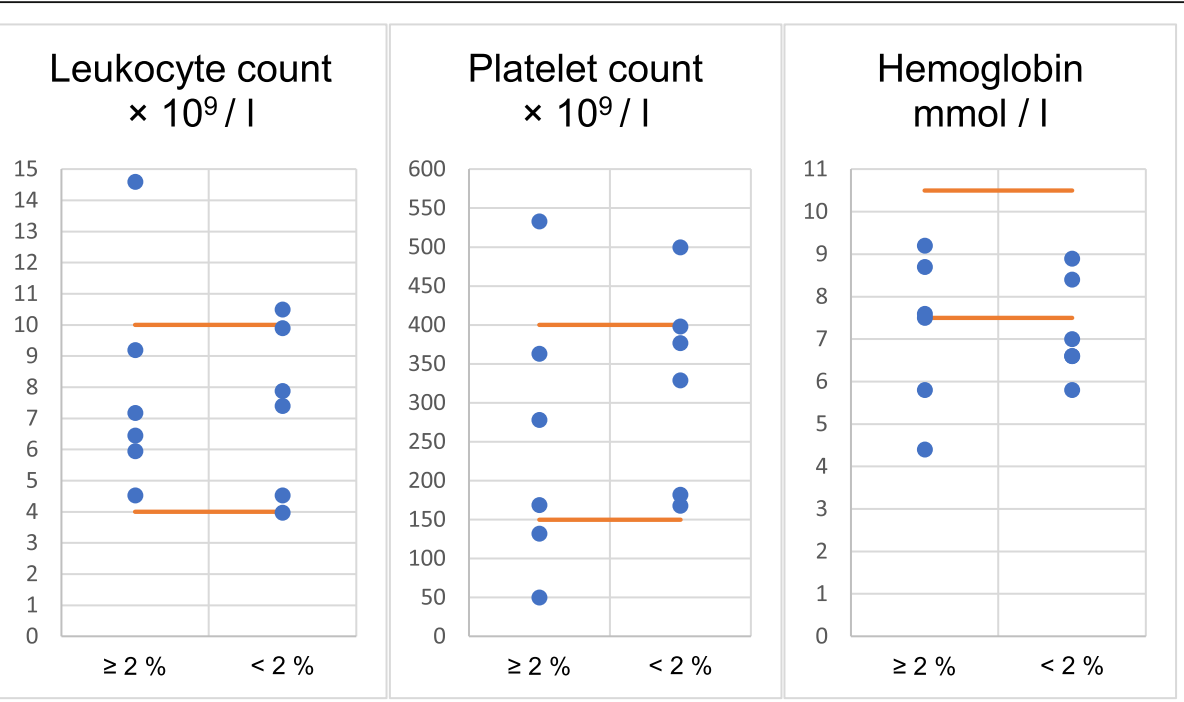

Fig. 1 Blood cell counts of patients with mutation of JAK2 V617F or MPL W515R according to variant allele frequencies: Frequency above the conventional detection limit $(\geq 2 \%)$ versus low allele frequency $(<2 \%)$. Orange lines show the minimum and maximum limits of the standard values

[6]: During a median follow-up time of 64 months nine patients with presence of JAK2 V617F at the time of SVT developed MPN and six new cases of JAK2 V617F mutated MPN were detected.

The existence of low and ultralow cancer associated $\mathrm{VAF}$ is of interest as the lately identified $\mathrm{ARCH}$ may represent a pre-manifestation event in patients showing no further criteria for hematologic neoplasms [7]. Follow-up data and studies on larger patient cohorts are warranted to further illustrate the relation of JAK2 and MPL ultralow VAF in the pathogenesis of SVT per se and the manifestation of MPN.

In view of highly sensitive molecular diagnostic tools conventional diagnostic criteria and definition of pathological conditions/diseases may need reconsideration.

\section{Supplementary Information}

The online version contains supplementary material available at https://doi. org/10.1186/s40364-020-00254-9.

\section{Additional file 1.}

\begin{abstract}
Abbreviations
ARCH: age-related clonal hematopoiesis; CALR: Calreticulin receptor; ddPCR: digital droplet polymerase chain reaction; DNA: Deoxyribonuclease Acid; JAK2: Janus kinase 2; I: Liter; mmol: Millimole; MPL: Thrombopoietin receptor; MPN: Myeloproliferative neoplasms; ng: Nanogram; NGS: Next Generation Sequencing; n.k.: Not known; No. : Number; PCR: Polymerase chain reaction; SVT: Splanchnic vein thromboses; VAF: Variant allele frequencies; WHO: World Health Organization
\end{abstract}

\section{Acknowledgements}

The clinical trial was supported by a grant of the Society for Internal Medicine Mecklenburg-West Pomerania (Gesellschaft der Internisten Mecklenburg-Vorpommerns e. V.).

\section{Authors' contributions}

LG: participation in patient recruitment, NGS analyses, data analyses, partial manuscript drafting. CGT: participation in study design. SiS: participation NGS. SK: primary sample handling, NGS panel evaluation. GK: nucleic acid isolation, NGS. CR: partial study design, partial database establishment. CJ: initial study design, general study supervision. LH: partial study design, supervision patient inclusion, recruitment, clinical data interpretation, partial manuscript drafting. HME: supervision all molecular work packages, study design, partial manuscript drafting. The authors read and approved the final manuscript.

\section{Funding}

The trial was supported by a grant of the Society for Internal Medicine Mecklenburg-West Pomerania (Gesellschaft der Internisten MecklenburgVorpommerns e. V.)

\section{Availability of data and materials}

The datasets used and/or analysed during the current study are available from the corresponding author on reasonable request.

\section{Ethics approval and consent to participate}

The study ("Prevalence of JAK2 Mutations in Patients with Abdominal Vein Thromboses") has been approved by the ethic committee of Rostock University Medical Center (Ethikkommission an der Medizinischen Fakultät der Universität Rostock, approval of 22th November 2016, A 2016-0200). Each patient submitted written informed consent to participate in the study.

Consent for publication

Not applicable.

\section{Competing interests}

The authors declare that they have no competing interests.

Received: 21 September 2020 Accepted: 3 December 2020

Published online: 14 December 2020

\section{References}

1. How J, Zhou A, Oh T. Splanchnic vein thrombosis in myeloproliferative neoplasms: pathophysiology and molecular mechanisms of disease. Ther Adv Hematol. 2017:8(3):107-18.

2. Passamonti F, Maffioli M. Update from the latest WHO classification of MPNs: a user's manual. Hematology Am Soc Hematol Educ Program. 2016;1: 534-42. 
3. de Stefano V, Qi X, Betti S, Rossi E. Splanchnic vein thrombosis and myeloproliferative neoplasms: molecular-driven diagnosis and long-term treatment. Thromb Haemost. 2016;115(2):240-9.

4. How J, Trinkaus KM, Oh ST. Distinct clinical, laboratory and molecular features of myeloproliferative neoplasm patients with splanchnic vein thrombosis. Br J Haematol. 2018;183(2):310-3.

5. Shlush LI. Age-related clonal hematopoiesis. Blood. 2018;131(5):496-504

6. Colaizzo D, Amitrano L, Guardascione MA, Tiscia GL, D'Andrea G, Longo VAC, et al. Outcome of patients with splanchnic venous thrombosis presenting without overt MPN: a role for the JAK2 V617F mutation reevaluation. Thromb Res. 2013;132(2):e99-e104.

7. McKerrell T, Park N, Chi J, Collord G, Moreno T, Ponstingl H, et al. JAK2 V617F hematopoietic clones are present several years prior to MPN diagnosis and follow different expansion kinetics. Blood Adv. 2017;1:268-71.

\section{Publisher's Note}

Springer Nature remains neutral with regard to jurisdictional claims in published maps and institutional affiliations.

Ready to submit your research? Choose BMC and benefit from:

- fast, convenient online submission

- thorough peer review by experienced researchers in your field

- rapid publication on acceptance

- support for research data, including large and complex data types

- gold Open Access which fosters wider collaboration and increased citations

- maximum visibility for your research: over $100 \mathrm{M}$ website views per year

At BMC, research is always in progress.

Learn more biomedcentral.com/submissions 